\title{
AGENESIS OF THYROID LOBE : A CASE REORT
}

\section{NAKHATE M.S. ${ }^{*}$ AND NAKHATE S.V. ${ }^{2}$}

1Department of Anatomy, Padmashree Dr. D.Y. Patil Medical College, Hospital and Research Center, Nerul, Navi Mumbai- 400706, MS, India. 2Thane Health Care Hospital, Thane- 400602, MS, India.

*Corresponding Author: Email- manishanakhate@yahoo.com

Received: May 05, 2013; Accepted: May 21, 2013

Abstract- The clinical presentation of congenital absence of one thyroid lobe is rare. Thyroid hemiagenesis is a rare anatomical anomaly which may be found in presence of any type of thyroid.

Keywords- Hemi aplsia, thyroid lobe agenesis, thyroid Gland - Grave's disease

Citation: Nakhate M.S. and Nakhate S.V. (2013) Agenesis of Thyroid Lobe : A Case Report. Medical Case Reports, ISSN: $0976-8726$ \& EISSN: 0976-8734, Volume 4, Issue 1, pp.-47-48.

Copyright: Copyright@2013 Nakhate M.S. and Nakhate S.V. This is an open-access article distributed under the terms of the Creative Commons Attribution License, which permits unrestricted use, distribution and reproduction in any medium, provided the original author and source are credited.

\section{Introduction}

Thyroid hemiagenesis is congenital anomaly is which one lobe of thyroid fails to develop, and was first described by Marshall in 1985 [1]. The more recent literature suggests that aplasia of one lobe of thyroid gland is rare and is diagnosed only because of concurrence of hyperthyroidism, adenocarciroma and colloid goiter [2,3].

Although hemiagenesis of thyroid gland is a benign condition lack of awareness of its existence may lead to an incorrect diagnosis.

\section{Case Report}

The purpose of this report is to describe a patient with hemiagenesis without any thyroid disorder presentation. Till the age of 79 years patient led a normal life, except late age osteoporosis. Patient had intolerance to cold but his thyroid function tests were in normal limits. He had suffered an attack of right hemi paresis and was known case of absence seizures for last 15 years.

Patient's Name : Moreshwar Avachat

Age : 77

Date : $12-08-2010$

Lab Number : AZB1239

The Complete Blood count [Table-1] and T3, T4, TSH observation reports [Table-2] of the above individuals are as shown.

\section{Multislice CT Scan of Chest Reveals}

Multislice CT scan of Patients chest [Fig-1] is done, that reveals

- Post infective sequalae noted with the patchy areas of consolidation in the left upper lobe.

- Few 5-7 mm mediastinal lymphnodes seen in the aorto pulmonary window. Atherosclerotic changes seen in the aortic arch.
- Multiple osteoporotic compression fractures with collapse seen in the lower dorsal spine. Incidentally noted nodule in the right lobe of thyroid with non-visualisation of the left lobe. Incidentally noted is a cyst in the right lobe liver.

\section{Table 1- Complete Blood Count}

\begin{tabular}{lcc|}
\hline Test Done & Observed Value & Normal Range \\
\hline Erythrocyte Count & 4.64 & $4.2-5.4 \mathrm{M} / \mathrm{CMM}$ \\
Haemoglobin & 11.3 & $12.5-16 \mathrm{GM} \%$ \\
P.C.V & 38.5 & $37-47 \%$ \\
M.G.V & 82.9 & $78-100 \mathrm{CU}$ Microns \\
M.C.H & 24.3 & $27-31 \mathrm{PG}$. \\
M.C.H.C & 29.3 & $32-36 \%$ \\
RDW & 14.9 & $11.5-14 \%$ \\
Platelets & 1.95 & $1.5-3.4$ Lakhs/CMM \\
Leucocyte Count & 6300 & $4000-11500 / \mathrm{CMM}$ \\
\hline Differential Count & & \\
\hline Neutrophils & 50 & $40-75 \%$ \\
Lymphocytes & 45 & $20-45 \%$ \\
Eosinophils & 3 & $1-10 \%$ \\
Basophils & 0 & $0-1 \%$ \\
Monocytes & 2 & $1-10 \%$ \\
Band Cells & 0 & \\
Other Abnormal W.B.C & Absent \\
RBC Morphology & Normochromic Normocytic \\
Platelets on smear & Adequate \\
\hline
\end{tabular}

Table 2- T3, T4, TSH observation report

\begin{tabular}{|lcc|}
\hline Test Done & Observed Value & Normal Range \\
\hline Thyroid Hormone Assay & & \\
T3 (Tri-ido Thyroine) & 84.42 & $59-152 \mathrm{ng} / \mathrm{dl}$ \\
T4 (Tetra ido-thyroine) & 5.98 & $4.6-12.5 \mathrm{ug} / \mathrm{dl}$ \\
T.S.H. (Thyroid stimulating hormone) & 1.017 & $0.25-5 \mathrm{uiu} / \mathrm{ml}$ \\
\hline
\end{tabular}




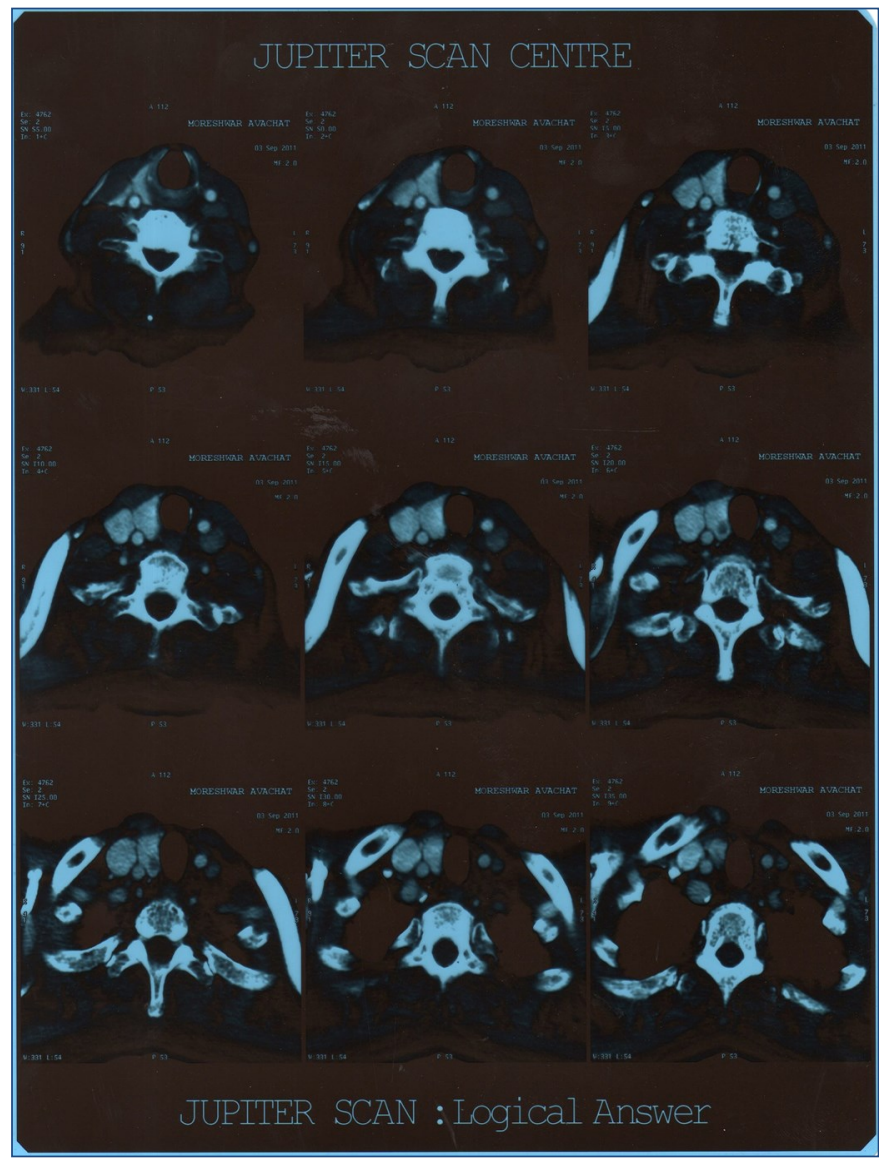

Fig. 1- Multislice post contrast CT scan of Chest

\section{Discussion}

The actual incidence of thyroid hemiagenesis is unknown, since in most of the cases the diagnosis was made coincidentally usually in patients submitted to thyroid scans or surgeries because of other thyroid anomalies. The studies done till now show maximum incidence in females and also association with hypothyroidism, benign goitre or carcinoma.

Marshall [1] found right lobe to be absent in one of the be child hood thyroid glands who examined specifically to know type and frequency if a anomalies of this gland.

Hemi agenesis of left lobe was detected at surgery in India by Das [4].

In 1972 Harda, et al [5] from Japan reported 7 cases that had been with neck exploration for thyroid disorders.

In 1973, Goolinger [6] reported a case during surgery in a euthyroid patient with a thyroid scan showing uptakes only on one side.

Tashima, et al [7] reported a case detected in 1973 detected on thyroid scanning.

Avramides, et al [8] in 1977 collected a total of 33 cases from the unexpected finding.

Hemi agenesis is a rarest of possibility which must be kept in mind. Most of the reported cases so far were in women and affected the right lobe predominantly but present case was reported in male of 79 years old who was asymptomatic throughout the life with left (lobe agenesis) hemi agenesis of thyroid.

\section{References}

[1] Marshall C.F. (1895) J. Anatomy \& Physiology, 29, 234-239.
[2] Burman K.D., Adler R.A., Wortosky L. (1975) Am. J. Med., 58 (1), 143-146.

[3] Hamburger J.I. and Hamburger S.W. (1970) Arch. Surg., 100, 319-320.

[4] Das P. (1962) J. Ind. Med. Assoc., 39302-304.

[5] Harada T., Nishikawa Y. and Ito K. (1972) Amer. J. Surg., 124, 617-619.

[6] Goolinger R.C. (1973) J. Amer. Med. Assoc., 224, 128.

[7] Tashima C.K., Lee W.Y. and Leong A. (1973) J. Amer. Med. Assoc., 224, 1761-1762.

[8] Avarmides A., Vichayanrt, A. Solmen N. and Carter A.C. (1977) Year Book of Nuclear Medicine, Year Book Medical Publishers, 61.

[9] Retnam V.J., Nayak V.N., Vernekar K.S., Bhandarkar S.D. (1981) J. Postgrad. Med., 27, 48-50. 